\title{
Dashboard Framework. A Tool for Threat Monitoring on the Example of Covid-19
}

\author{
Celina M. Olszak \\ University of Economics in Katowice \\ Poland \\ celina.olszak@ue.katowice.pl
}

\author{
Arkadiusz Kisiołek \\ University of Economics in Katowice \\ Poland \\ arkadiusz.kisiołek@,ue.katowice.pl
}

\begin{abstract}
The aim of the study is to create a dashboard framework to monitor the spread of the Covid-19 pandemic based on quantitative and qualitative data processing. The theoretical part propounds the basic assumptions underlying the concept of the dashboard framework. The paper presents the most important functions of the dashboard framework and examples of its adoption. The limitations related to the dashboard framework development are also indicated. As part of empirical research, an original model of the Dash-Cov framework was designed, enabling the acquisition and processing of quantitative and qualitative data on the spread of the SARS-CoV-2 virus. The developed model was pre-validated. Over 25,000 records and around 100,000 tweets were analyzed. The adopted research methods included statistical analysis and text analysis methods, in particular the sentiment analysis and the topic modeling.
\end{abstract}

\section{Introduction}

In modern times, socio-economic threats can take various forms [1, 16, 51]. They usually concern the following types of threats: (1) natural (floods, fires, droughts, smog), (2) technical (failures of energy and water systems), (3) terrorism, (4) weapons of mass destruction, (5) mass migrations, (6) social unrest (on the grounds of religion, racism, sexual views), (7) disturbances to public order, (8) organized crime (trafficking in arms, drugs, human trafficking), and recently, epidemic threats. Monitoring this type of threat plays a key role today. This consists in, for example, timely and objective transmission of up-to-date information about emerging dangers, sending alerts, dynamically responding to various situations, as well as taking preventive measures to reduce the risk of threats.

It is hard not to notice that threat monitoring is associated with the need to process enormous amounts of data, often with a complex and diverse structure. Processing this type of data requires the use of adequate tools and information technologies that would not only automate this process, but also enable the discovery of various associations (relationships) between the data. Newly discovered relationships may prove crucial in quick recognition of the first symptoms of emerging threats and responding to them appropriately.

The amount of data in the world is increasing at a dynamic pace [44]. It is estimated that each person generates an average of 1.7 MB of data per second [11]. Data are also generated by various devices, sensors, systems, and portals [3]. One of the most important data sources is the Internet [6]. Due to the constantly increasing volume of data as well as their volatility and complexity, the need for advanced data mining and analysis is emphasized $[15,39,43]$. It is thought that advanced data mining and metadata analysis constitute the basis for professional monitoring of contemporary socio-economic phenomena [28], including epidemic threats.

The theory and practice shows that Business Intelligence (BI) systems have repeatedly proven themselves in multidimensional data analysis and data mining, as well as in presenting large volumes of data in the form of dashboards [32]. For many years, the beneficiaries of BI systems have been industry, trade, energy, transport, finance, and many other sectors.

Considering the prevailing pandemic and the need for prompt analyses of the spread of the SARS-CoV-2 virus, BI systems, especially dashboards, seem to be an interesting solution supporting the monitoring of epidemic threats. Unfortunately, most of the existing dashboards usually use only quantitative data. This study aims to create an original dashboard framework (Dash-Cov) to monitor the spread of the SARS-CoV-2 virus based on quantitative and qualitative data processing. This dashboard framework focuses on acquiring, collecting, processing and analyzing data from various, distributed, heterogeneous data, including the Internet and social media. The aggregation of both quantitative and qualitative data brings a new value to the process of monitoring the spread of the virus. This 
enables the discovery of many hidden relationships between data that may indicate trends in the spread of SARS-CoV-2 and propose ways to fight this virus as well as to track people's behaviors in the face of a pandemic.

The developed model was pre-validated. Over 25,000 records from Kaggle website and around 100,000 tweets were gathered using R (via API) and analyzed. The collected and analyzed data were visualized based on Microsoft Power BI. The adopted research methods included statistical analysis and text analysis methods, in particular the sentiment analysis and topic modeling.

\section{Nature of dashboard}

Even the most advanced data analysis can be considered of little use when its results are not properly presented. There are many examples showing that it is not the amount of data, but the method of data presentation that determines their effective use [24, 34, 48, 49]. Appropriate data visualization has become a priority for many organizations that struggle with large amounts of data in the decision-making process [54]. Providing users with tools that, on the one hand, would be intuitive to use, and on the other, enable the presentation of data in various layouts and forms, has become a challenge for many IT system designers.

Recently, dashboards have been recognized as the most advanced form of data visualization. According to many authors, the dashboard is a tool for the visual presentation of data in the form of charts, tables, metrics, scorecards, maps, icons, and graphics [17, 29, 49]. The dashboard is often treated as a kind of interface, the purpose of which is to provide users with various information in the form of reports, alerts, and KPIs (Key Performance Indicators), concerning, e.g., the firm's condition and market trends [36]. Supported by dashboards, managers can better assess and understand the condition of the firm, the processes taking place in it, and the events that occur in its environment $[4,13$, 30, 50, 53].

According to many authors, the purpose of the dashboard is primarily to aggregate and present large data sets in a clear and convenient form [5, 18, 19]. In turn, [21] argued that one of the most important tasks of dashboards is monitoring KPIs to improve decision making. They can also be used to forecast various scenarios, support recommendation systems, and inform about emerging anomalies [38]. An overview of selected interpretations of the term "dashboard" is presented in Table 1.
Table 1. Overview of selected definitions of the dashboard term

\begin{tabular}{|c|c|}
\hline Source & Definition \\
\hline $\begin{array}{l}{[17,} \\
29,49]\end{array}$ & $\begin{array}{l}\text { Dashboard is a tool for the visual } \\
\text { presentation of data in the form of } \\
\text { charts, tables, metrics, scorecards, } \\
\text { maps, icons, and graphics. }\end{array}$ \\
\hline [53] & $\begin{array}{l}\text { The data dashboard is a collection of } \\
\text { periodically constructed indicators } \\
\text { for a responsible stakeholder to guide } \\
\text { decisions and actions toward } \\
\text { achieving performance goals. It is a } \\
\text { performance measurement tool that } \\
\text { facilitates the proactive management } \\
\text { of one or more activities as part of an } \\
\text { improvement process. A data } \\
\text { dashboard is also viewed as } \\
\text { a decision-supporting tool. }\end{array}$ \\
\hline [18] & $\begin{array}{l}\text { Dashboard provides the most } \\
\text { essential information that has been } \\
\text { collected and graphically presented } \\
\text { on the computer screen and is } \\
\text { required to attain one or more goals. }\end{array}$ \\
\hline $\begin{array}{l}{[4,21,} \\
36]\end{array}$ & $\begin{array}{l}\text { Dashboard is a graphical interface } \\
\text { that provides insight into key metrics } \\
\text { related to individual goals or } \\
\text { processes taking place in the } \\
\text { enterprise. }\end{array}$ \\
\hline [30] & $\begin{array}{l}\text { Dashboard is an intuitive tool that } \\
\text { provides a snapshot view of results } \\
\text { and trends, or "core" business } \\
\text { knowledge, such as trends and alerts. }\end{array}$ \\
\hline [13] & $\begin{array}{l}\text { Dashboard is a layered information } \\
\text { system that provides access to } \\
\text { information and alerts so that users } \\
\text { can measure, monitor, and manage } \\
\text { business performance more } \\
\text { effectively. }\end{array}$ \\
\hline [9] & $\begin{array}{l}\text { Dashboard is a term that is commonly } \\
\text { used in the context of business } \\
\text { analytics and is a popular way of } \\
\text { presenting relevant information. }\end{array}$ \\
\hline$[50]$ & $\begin{array}{l}\text { A dashboard is a visual display of } \\
\text { data used to monitor conditions } \\
\text { and/or facilitate understanding. }\end{array}$ \\
\hline $\begin{array}{l}{[5,18,} \\
19,56]\end{array}$ & $\begin{array}{l}\text { Dashboards provide a simple front } \\
\text { face for complex data while } \\
\text { supporting the correct decision- } \\
\text { making processes of the managers. At } \\
\text { the same time, they are sophisticated }\end{array}$ \\
\hline
\end{tabular}




\begin{tabular}{|l|l|}
\hline Source & Definition \\
\hline \multirow{5}{*}{} & $\begin{array}{l}\text { software applications that are } \\
\text { presented to users in a simple, fast } \\
\text { and complete way which interprets } \\
\text { the operational data with new } \\
\text { scientific and technological } \\
\text { approaches. }\end{array}$ \\
\hline 38$]$ & $\begin{array}{l}\text { Dashboards are used to forecast } \\
\text { various scenarios, support } \\
\text { recommendation systems, and inform } \\
\text { about emerging anomalies. }\end{array}$ \\
\hline
\end{tabular}

Dashboards have been used in many industries, especially in health care, marketing, public services, education, construction, music, banking, the Internet of Things, and manufacturing $[8,10,14,22,27,31,39,41$, 46, 47, 51, 55]. They are applied primarily in: (1) decision making - they provide opportunities to support decision-makers at all stages of the decisionmaking process, (2) knowledge management - they provide up-to-date and aggregated information, as well as information on emerging trends and anomalies, (3) data visualization - they present extensive data sets in an intuitive and graphical form, (4) strategic management - they are a useful tool for managerial staff at all levels of management, especially in making strategic decisions, (5) supporting business processes - they clearly illustrate the implementation of many management and administrative processes, e.g., documentation circulation, financial flows [12, 33, 35, 37] (Figure 1).

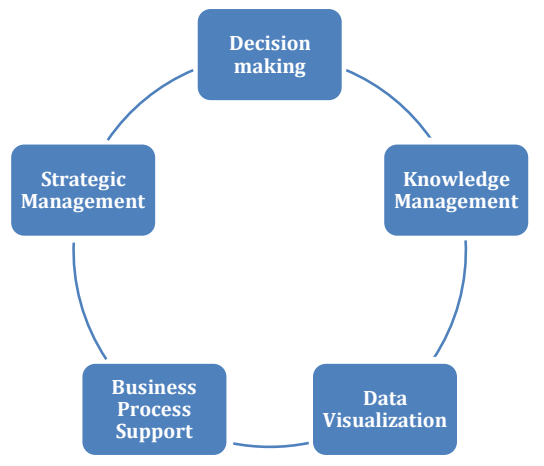

Figure 1. Dashboard usage areas in the organization

Source: own elaboration based on $[12,32,35,36]$

As stated before, dashboards are tools that use a very large amount of data. This fact implies the need to automate the process of data acquisition, processing, analysis, and visualization. This is connected with the necessity to use adequate technologies and software, which include, e.g., BI software, programming languages (e.g., R, Python), and e.g., the Hadoop engine.

The process of designing a dashboard consists of four basic stages. These are: (1) data acquisition from various sources, (2) data cleansing, standardizing, and processing, (3) data analysis and visualization, and (4) data sharing (Figure 2).

The goal of the data acquisition stage is to harvest and collect useful data from multiple dispersed and heterogeneous sources. The acquired data may be in the form of: (1) structured data (e.g., databases), (2) unstructured data (e.g., images, videos, audio files, posts in social media), (3) poorly structured data (e.g., XML files, RSS, JSON) [15, 26, 40].

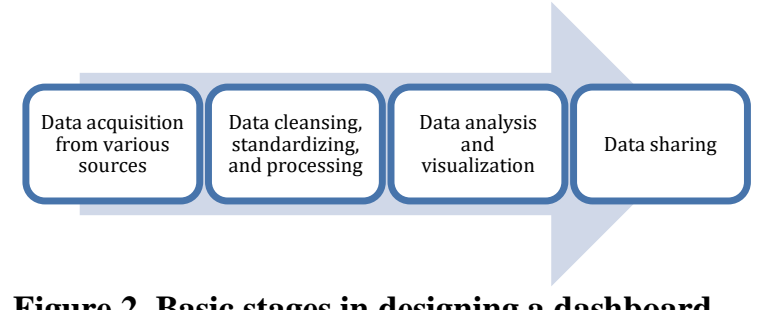

Figure 2. Basic stages in designing a dashboard

Source: own elaboration

The goal of the second stage is, first of all, cleansing and merging the acquired data, and then their storage. At this stage, the data are checked for correctness and integrity, in particular: (1) data cleansing, (2) data normalization, (3) missing data replacement, (4) reduction of data dimensions or sample size [2]. This stage is thought to be one of the most important and time-consuming stages in the design of dashboards.

Data analysis is the process of transforming and modeling data in order to obtain useful information as well as discover new knowledge. This analysis can be carried out using many methods, among which the following deserve special attention: descriptive statistics, factor analysis, discriminant analysis, correspondence analysis, basket analysis, cluster analysis, time series analysis, clustering, decision trees, neural networks, data drilling, regression analysis, and text analysis $[26,42]$. Subsequently, the data processed and analyzed in this way are visualized. Various techniques are used for this purpose, especially graphs, controls, scorecards, and maps.

The last stage, related to the design of dashboards, concerns data sharing. The presented results of analyses are sent to users who, in accordance with their rights and competences, receive aggregated metrics, summary statements, and various cross-sectional data. They are the basis for further analyses and decision making. 


\section{Examples of dashboard adoption}

There are many examples and benefits of using dashboards. For instance, Coca-Cola's implementation of dashboards led to full automation of the sales reporting process, which in turn saved about 260 manhours per year. Another example is HelloFish, where the entire marketing analysis system is based on dashboards. This saved the analyst team 10-20 manhours per day [45].

The spread of the pandemic triggered a great interest of health-care organizations and government administrations in dashboards. Information on the spread of Covid-19 is collected by various institutions: WHO, hospitals, health-care units, epidemic stations, and vaccination points. Timely, reliable, up-to-date, and consistent information, coming from various sources, has become a key factor in taking any measures to monitor and prevent the spread of Covid-19.

One of the best-known dashboards for monitoring the Covid-19 pandemic is the tool developed by the Johns Hopkins University School of Medicine (Figure 3). This dashboard presents quantitative data on the number of infected people, the number of deaths, and the number of tests performed geographically [23].

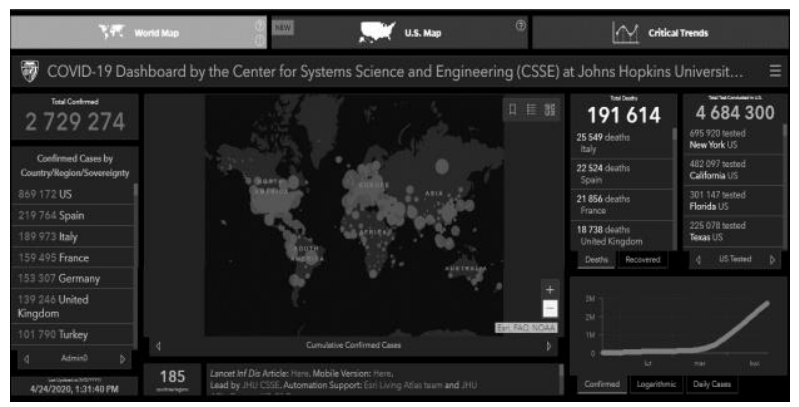

Figure 3. A dashboard presenting data on the Covid-19 pandemic prepared by the Johns Hopkins University Source: [23]

Another well-known tool for presenting data on the Covid-19 pandemic is the dashboard developed by the World Health Organization. The dashboard enables the presentation of data in various angles, e.g., as part of a heat map and a bubble chart. The data are presented on the map and in line charts in aggregated form (Figure $4)$.

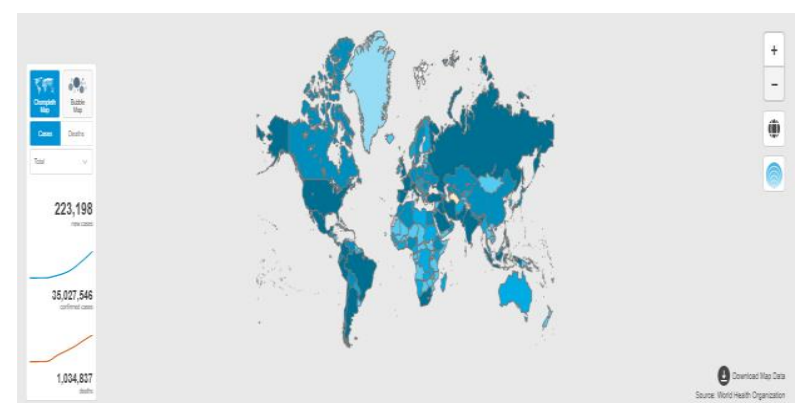

Figure 4. A dashboard presenting data on the Covid-19 pandemic prepared by the World Health Organization

Source: [52]

Yet another dashboard dedicated to the presentation of data on the spread of Covid-19 is the Austin Texas Covid-19 Dashboard (Figure 5) and the dashboard generated in the Google search engine (Figure 6).

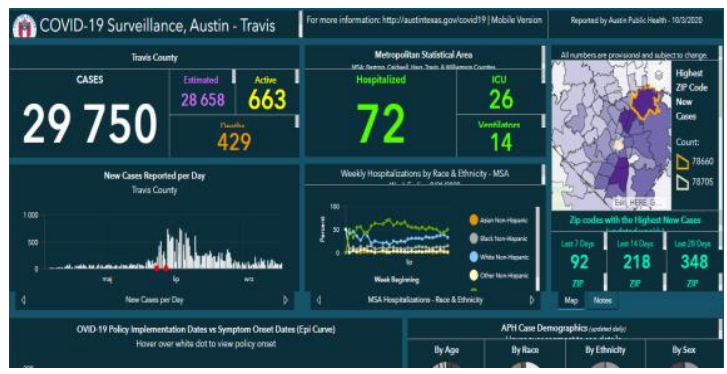

Figure 5. A dashboard showing Covid - 19 cases around the world prepared by the city of Austin, Texas Source: [7]

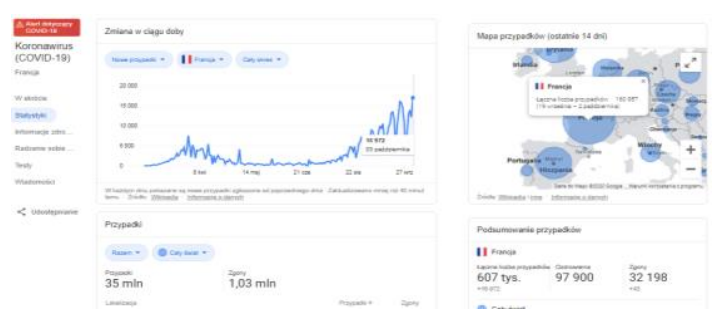

Figure 6. The dashboard presented in Google search results

Source: [20]

The dashboards mentioned provide users with a similar range of data. The data usually concern: the number of new infections, the number of deaths, the number of tests performed, the number of convalescents, and the number of hospitalized persons. These data are presented in charts, maps, controls, with the use of various levels of aggregation (e.g., based on time or region). The dashboards presented are 
characterized by a rather simple and intuitive operation. They are mainly supplied with numerical data from various databases, spreadsheets, and files. Unfortunately, they do not offer the possibility of acquiring and processing qualitative data, e.g., from social media and blogs, containing posts, entries, comments of Internet users as well as their reactions and emotions.

The next section of this paper provides a new knowledge concerning a design and development of original dashboard framework to monitor the spread of the SARS-CoV-2 virus based both on quantitative and qualitative data. The proposed dashboard offers rapid access to different, heterogeneous, dispersed information resources, their analysis, and visualization. It enables the aggregation of multiple sources of data some of which are not presented in the existing dashboards. In other words, the proposed dashboard uses not only the daily data published by governmental and medical entities, but also contents created on different social media platforms like Twitter. It provides richer insights compared to existing dashboards by the means of diverse analysis such as sentiment analysis, social media mining, and topic modeling.

\section{Dashboard framework proposal - Dash- Cov}

The empirical goal of this study is to develop a DashCov framework to monitor the spread of the Sars-Cov2 virus based on both quantitative and qualitative data processing. The verification of the developed model was carried out with the use of data from: (1) the Kaggle website [25] for the statistics of recorded Covid-19 infections and (2) the Twitter website for the phrases used by Internet users in the context of the Covid-19 pandemic. The research sample consisted of: 25,000 records of Covid-19 cases worldwide (from the Kaggle website) and 100,000 tweets about the Covid-19 pandemic.

The $\mathrm{R}$ programming platform was used to acquire the data mentioned. However, for data processing, analysis and visualization, Microsoft Power BI software was mainly used. The data analysis also adopted statistical methods and methods of text analysis, including the sentiment analysis and top modeling.

The developed dashboard framework - Dash-Cov consists of five modules: (1) data collection, (2) data preparation, (3) data analysis, (4) knowledge presentation, and (5) alerting. The proposed Dash-Cov framework was pre-validated. The concept behind individual Dash-Cov modules is presented below (Figure 7).

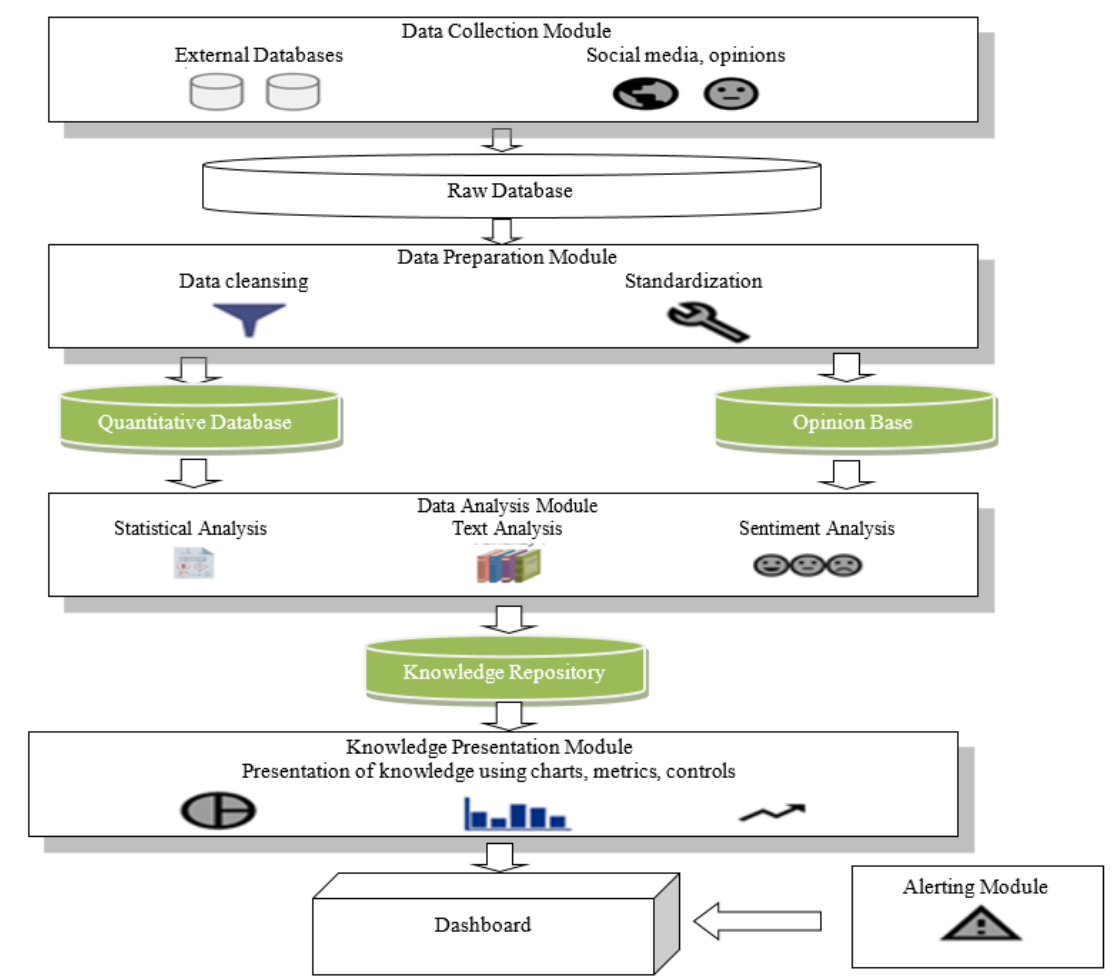

Figure 7. The Dash-Cov framework architecture 
The basic element of the Dash-Cov framework is the data collection module, which is used to supply the dashboard database. Among the many data sources supplying the dashboard there are mainly external databases (on the Covid-19 statistics) and social media (tweets about the Covid-19 pandemic). The data are downloaded automatically via API and updated at defined time intervals. The effect of the data collection stage is the creation of a repository containing up-todate and reliable data.

The purpose of the second Dash-Cov module - data preparation - is primarily: (1) checking the rules of correct data recording, (2) removing white characters, duplicate values and other errors resulting from the data acquisition process, (3) unifying the encoding of text data and the manner of representing numerical data, (4) supplementing missing data, and (5) removing the socalled stopwords from textual data, i.e., words that do not affect the context of the post. Ultimately, the data prepared in this way are merged and collected in appropriate subsets: the quantitative data repository and the opinion base.

Next module that makes up the Dash-Cov framework is the data analysis module. This module uses various methods, in particular: (1) methods of statistical analysis in terms of quantitative data and (2) methods of text analysis (including the sentiment analysis and the topic modeling) in terms of qualitative data. Statistical analysis is especially helpful in answering various questions about the scale of the spread of the Covid-19 pandemic, e.g., broken down into individual continents, regions, cities (Figure 8). Data analyzed in this way are collected in the knowledge repository and then transferred to the knowledge presentation and visualization module. The purpose of this module is to provide the user with a simple, consistent, and easy-to-use dashboard.

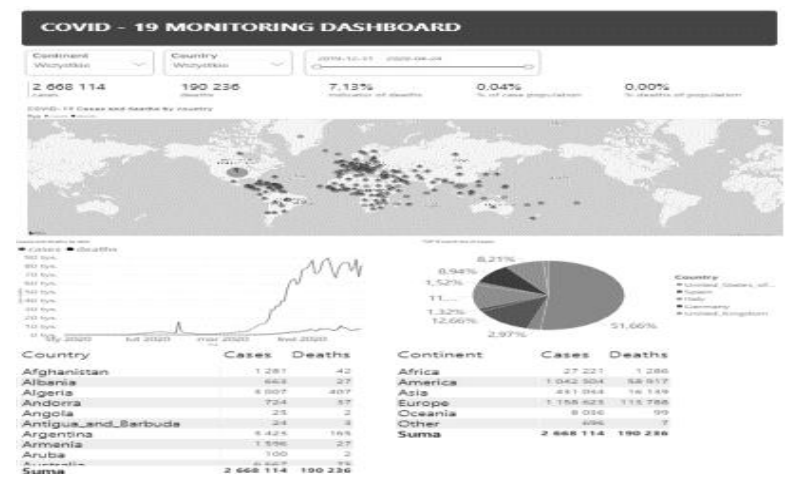

Figure 8. Presentation of quantitative data using the Dash-Cov framework

A unique feature and value of proposed Dash-Cov framework is manifested in the analysis of qualitative data. By analyzing the posts of Internet users, i.e., the most frequently used phrases or words, it is possible to discover and better understand their attitudes, preferences, and emotional attitudes towards the spread of the pandemic.

This research, to explore qualitative data, uses mainly text mining approach. The aim of text mining analysis is gathering information from various text data sources (e.g., social media, forums, papers, e-mails). Text mining refers to text classification, text clustering, and ontologies [17]. One of the text mining techniques, applied in this research is the sentiment analysis (opinion mining) and the topic modeling.

As mentioned above, the Dash-Cov framework uses the method of tweet sentiment analysis about the Covid19 pandemic to examine the qualitative data (Figure 9). The provided sentiment analysis is based on the augmented dictionary method. This technique involves an algorithm assigning appropriate weights to individual opinions, based on the words used in such opinions. The method used takes into account contextual valence shifters, e.g., negators, amplifiers, de-amplifiers, and adversative conjunctions. Negative opinions are assigned negative weights, positive opinions - positive weights, and neutral opinions are assigned a value of 0 .

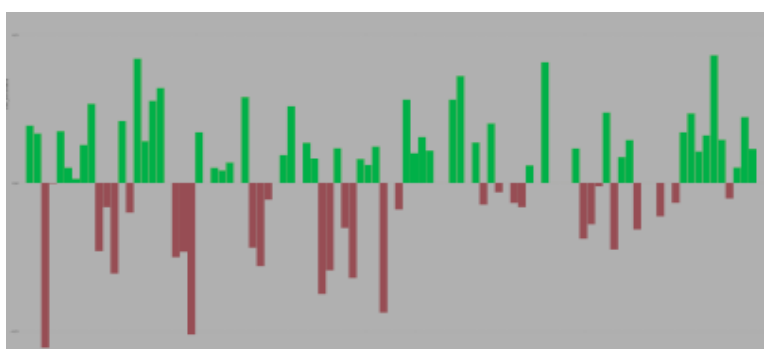

Figure 9. Sentiment analysis for tweets about the Covid-19 pandemic

For example, on the basis of the sentiment analysis mentioned, it was found that less than $48 \%$ of tweets were positive, $16 \%$ neutral, and $36 \%$ negative. The vast majority of the surveyed tweets were characterized by a relatively low degree of emotional load. However, it should be remembered that this does not mean that there were no extreme opinions (strongly negative or strongly positive).

The sentiment analysis method was also used to conduct more in-depth research. It turned out to be helpful in discovering a new knowledge concerning users' emotions related to the Covid-19 topic. The research showed that over $20 \%$ of users' tweets were classified to "trust" category. Fewer users' tweets were related to "fear," "anticipation," "sadness," and "joy" categories. The fewest of user's tweets were associated with "anger," "surprise," and "disgust" categories (Figure 10). 


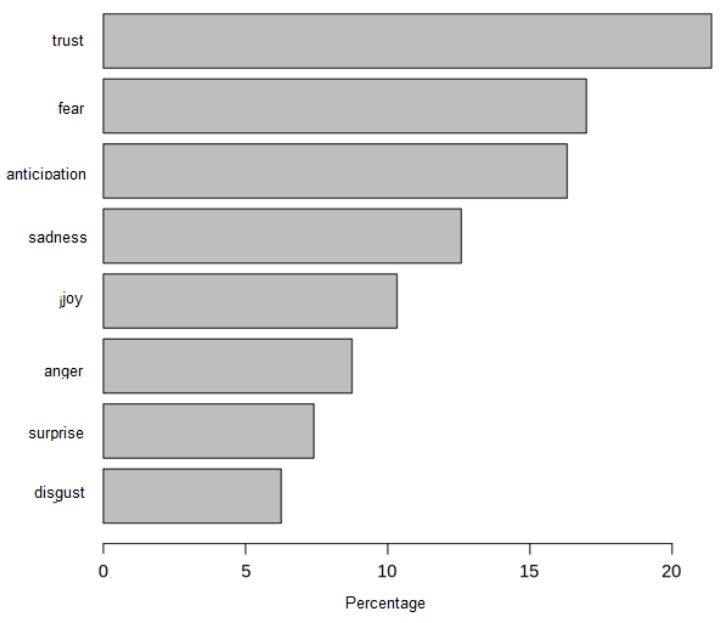

Figure 10. Specific emotions for tweets about the Covid-19 pandemic

This research has illustrated that there is a correlation between the daily number of infections and the emotional attitude of Twitter users to the Covid-19 pandemic. In the tested time series, there was a moderate negative correlation $(R=-0.33)$ between the number of infections and the emotional load of the studied tweets. This means that along with the increase in the number of infections, the emotional character of tweets in the studied sample worsened. The results of the analysis also showed that the increase in the number of infections resulted in a deterioration of the emotional load of tweets even after several days.

The next interesting analysis method used in the proposed dashboard is topic modeling [57]. It allows to find a hidden pattern in text data and divide these data into groups (topics). The result of such an analysis, based on Non-Negative Matrix Factorization, is presented in Table 2.

Table 2. Finds of selected topic groups in Covid19 tweets

\begin{tabular}{|l|l|l|l|l|}
\hline Topic 1 & Topic 2 & $\begin{array}{l}\text { Topic } \\
3\end{array}$ & $\begin{array}{l}\text { Topic } \\
4\end{array}$ & Topic 5 \\
\hline coronavirus & world & case & mask & scenario \\
\hline covid & people & new & wear & option \\
\hline pandemic & health & report & safe & $\begin{array}{l}\text { post(pand } \\
\text { emic) }\end{array}$ \\
\hline lockdown & global & death & need & grow \\
\hline infection & help & total & help & education \\
\hline
\end{tabular}

Table 2 displays the 5-topic solution of the topic modeling analysis and lists 5 terms for each topic. Selected topics concerned: (1) Covid-19 pandemic in general, (2) Covid-19 influence on people, (3) Covid-19 reporting, (4) Covid-19 protection, and (5) Covid-19 forecasts.
Additionally, Dash-Cov framework illustrates how the text analysis method can be used to find the most frequently spoken words by users. The list of such words was elaborated with the help of word cloud, also known as a tag cloud. Data presented in this way (Figure 11) are interpreted in accordance with the principle: the larger the font of a given word is, the greater is the frequency of its occurrence or greater share in the analyzed structure.

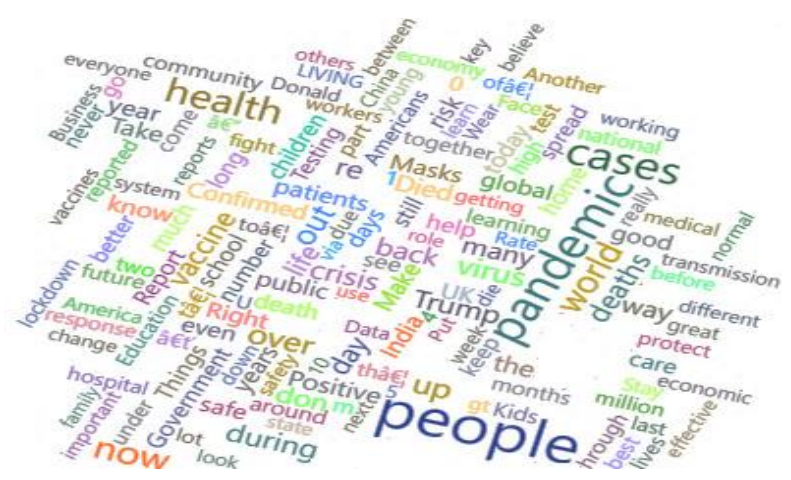

Figure 11. Cloud of frequently used words in tweets about the Covid-19 pandemic

This research showed that among the most frequently used words in tweets concerning the Covid19 pandemic, there were: "people," "health," "cases," "crisis," "vaccine," "everyone," "lockdown," "protect," "mask," "transmission." Commenting on the crisis caused by the Covid-19 pandemic, the Internet users paid special attention to the need to use a variety of personal protective equipment (e.g., masks) and the need to invent an effective vaccine. Twitter users often mentioned the virus transmission and "lockdown" which affected most countries in the world.

The developed Dash-Cov framework provides information mainly in the form of tables and graphs. It was also equipped with an alerting module. The main task of this module is to inform users about new emerging threats related to the Sars-Cov-2 virus, as well as about applied restrictions and recommendations. Various data mining techniques, such as data mining and web mining, have been implemented in the alerting module. Alerts are usually sent to users in the form of e-mail messages.

\section{Conclusions}

The obtained research results allow for the conclusion that dashboards can be an effective tool for monitoring pandemic data. Unfortunately, most dashboards developed are based only on quantitative data. Such data are obtained from various sources 
related to broadly understood health protection. Limiting analyses to quantitative data only, in the authors' opinion, significantly limits the spectrum of knowledge about the spread of Covid-19 pandemic. Qualitative information, including the opinions and posts of Internet users about the SARS-CoV-2 virus, can be extremely helpful in creating an overall picture in this regard. Such information is a valuable source that should be analyzed and presented in parallel with the results from analyses based on quantitative data.

Accordingly, the research developed a Dash-Cov framework that uses both quantitative and qualitative data in its operation. This model was pre-validated. The developed Dash-Cov framework consists of modules responsible for: data collection, preparation, analysis, presentation and alerting, respectively. The data repository created as part of Dash-Cov is a collection of quantitative and qualitative data. For the analysis of quantitative data in Dash-Cov, statistical methods and Microsoft Power BI software are mainly used.

The analysis of qualitative data adopted, by and large, the text, tweet, and sentiment analysis. Among others, phrases that were most often used in tweets about the Covid-19 pandemic were analyzed. The sentiment analysis of those tweets was also carried out.

The obtained research results enrich our knowledge about the spread of Covid-19 pandemic. The developed dashboard framework can be used by health-care organizations, government administration, and the media. It enables swift identification and forecast of the directions of the virus spread and comprehensive benchmarking on various measures aimed at preventing the spread of the pandemic by individual countries. The model also analyzes the opinions of ordinary people about Covid-19, their reactions, behavior, and attitudes towards, for example, vaccines.

The developed Dash-Cov framework requires further research and validation. This applies, inter alia, to the need to obtain data from more databases and social media, as well as the use of efficient algorithms for automatic cleansing, standardizing, and merging of data. The exploration of new dependencies between data that may indicate emerging new threats also requires further work and analyses. Furthermore, a lot of work needs to be done in terms of the effective functioning of the alerting module. The module requires greater personalization and cooperation with various specialists in terms of agreeing the content of sent messages and alerts.

This study may turn out to be interesting for scientists dealing with data analysis and dashboard design, as well as for health-care and public administration institutions responsible for sharing a wide range of data on the spread of the Covid-19 pandemic.

\section{References}

[1] Abedin B., Babar A. (2018), "Institutional vs. Noninstitutional use of Social Media during Emergency Response: A Case of Twitter in 2014 Australian Bush Fire", Information Systems Frontiers, 20, pp. 729-740.

[2] Acuña E. (2011), "Preprocessing in Data Mining", In: M. Lovric (eds), International Encyclopedia of Statistical Science, Springer, Berlin, Heidelberg, pp. 1083-1085.

[3] Ajah I.A., Nweke H.F. (2019), "Big Data and Business Analytics: Trends, Platforms, Success Factors and Applications", Big Data and Cognitive Computing, Vol. $3(2)$, 32, retrieved from https://www.mdpi.com/25042289/3/2/32.

[4] Alexander M., Walkenbach J. (2013), Microsoft Excel. Dashboards \& Reports. Canada: Wiley Publishing, pp. $11-28$.

[5] Anderson D. R. , Sweeney D.J., Williams T.A., Camm J.D., Cochran J.J. (2017), Essentials of Modern Business Statistics with Microsoft Office Excel (Book Only). Cengage Learning, pp. 1-108.

[6] Askitas N., Zimmermann K. (2015): The internet as a data source for advancement in social sciences, International Journal of Manpower, 36. pp. 2-12.

[7] Austin, 2020, Austin Texas Covid Dashboard, retrieved from

https://austin.maps.arcgis.com/apps/opsdashboard/index .html\#/39e4f8d4acb0433baae6d15a931fa984.

[8] Banerjee S., Saini A., Nigam H., Vijay V. (2020), "IoT Instrumented Food and Grain Warehouse Traceability System for Farmers", International Conference on Artificial Intelligence and Signal Processing (AISP), Amaravati, India, pp. 1-4.

[9] Browne D., Desmeijter B., Dumont R., Kamal A., Leahy J., Masson S., Rusak K., Yamamoto Y., Keen M. (2010), IBM Cognos Business Intelligence, Handbook. IBM Redbooks, pp. 162.

[10] Bruni A., Cassia F., Magno F. (2017), "Marketing performance measurement in hotels, travel agencies and tour operators: a study of current practices", Current Issues in Tourism, 20, pp. 339-345.

[11] DOMO (2018), Data never sleeps, 6.0, retrieved from https://www.domo.com/assets/downloads/18_domo_dat a-never-sleeps-6+verticals.pdf.

[12] Dragomirescu S.E., Solomon D.C. (2013), "The role of the performance dashboard in the management of modern enterprises", Studies and Scientific Researches. Economics Edition, Vol. 18, pp. 166-176.

[13] Eckerson W. (2011): Performance Dashboards: Measuring, Monitoring, and Managing Your Business. John Wiley \& Sons, Inc, pp. 11.

[14] Ernst C.P.-H., dos Santos A. (2021), "Business Intelligence in the Database Marketing - A Case Study of a German Insurance Company", Proceedings of the 54th Hawaii International Conference on System Sciences, pp. 1011-1019. 
[15] Erraissi A., Belangour A. (2018), Data sources and ingestion big data layers: meta - modeling of key concepts and features. International Journal of Engineering \& Technology, 7 (4), pp. 3607-3612.

[16] Fehler W. (2007), Zagrożenie - kluczowa kategoria teorii bezpieczeństwa, in: K. Jałoszyński, B. Wiśniewski, T. Wojtuszek (eds.), Współczesne postrzeganie bezpieczeństwa, WSA, Bielsko-Biała, pp. 42.

[17] Feinerer I.K. Hornik K., Meyer D. (2008), Text Mining Infrastructure in R, "Journal of Statistical Software", Vol. 25, Iss. 5, s. 1-54.

[18] Few S. (2013), Information Dashboard Design. Displaying data for at-a-glance monitoring, Analytics Press, Burlingame, pp. 26.

[19] Garwood K., Steingard D., Balduccini M. (2020), "Dynamic Collaborative Visualization of the United Nations Sustainable Development Goals (SDGs): Creating an SDG Dashboard for Reporting and Best Practice Sharing", Proceedings of the 15th International Joint Conference on Computer Vision, Imaging and Computer Graphics Theory and Applications - IVAPP, pp. $294-300$.

[20] Google, 2020, “COVID - 19 Dashboard”, retrieved from https://www.google.com/search?q=france+covid+dashb oard\&oq=france+covid+dashboard\&aqs=chrome. 0.012 . 3785j0j9\&sourceid=chrome\&ie $=$ UTF-8\&safe $=$ images .

[21] Gómez C., Ayala C.P., Franch X., López L., Behytiye W., Martinez-Fernandez S. (2017), "Towards an ontology for strategic decision making: The case of quality in rapid software development projects", International Workshop on Conceptual Modelling in Requirements and Business Analysis, Advances in Conceptual Modelling: ER 2017 Workshops AHA, MoBiD, MREBA, OntoCom, and QMMQ: Valencia, Spain, Springer, pp. 111-121.

[22] Hettiarachchi S., Proboshena D., Stembo L., Rajapaksha H., de Silva R., Nawinna D. (2019), “An Integrated Platform of Water Quality Management for National Water Supply and Drainage Board", 14th Conference on Industrial and Information Systems (ICIIS), Kandy, Sri Lanka, 2019, pp. 192-197.

[23] Hopkins, 2020, COVID - 19 Dashboard by the Center for Systems Science and Engineering (CSSE) at Jonhs Hopkins University, retrieved from https://coronavirus.jhu.edu/map.html.

[24] In, J., \& Lee, S. (2017). Statistical data presentation. Korean journal of anesthesiology, 70(3), 267-276. https://doi.org/10.4097/kjae.2017.70.3.267.

[25] Kaggle, 2020, COVID - 19 Geographic distribution (Coronavirus), COVID - 19 Coronavirus data - European Centre for Disease Prevention and Control, retrieved from

https://www.kaggle.com/cristiangarrido/covid19geograp hicdistributionworldwide.

[26] Kathula P. (2021), Hands-on Data Analysis and Visualization with Pandas: Engineer, Analyse and Visualize Data, Using Powerful Python Libraries, BPB Publications.

[27] Kirithika S, Madhan Kumar L., Kingson Kumar M., Keerthana E., Lohalavanya R. (2020), "Smart Public Toilets using IoE: International Conference on Emerging
Trends in Information Technology and Engineering (ICETITE), Vellore, India, pp. 1-5.

[28] Kubina M., Varmus M., Kubinova I. (2015), "Use of big data for competitive advantage of company", Procedia Economics and Finance, 26, pp. 561-565.

[29] Larson B. (2020), Data Analysis with Microsoft Power BI, McGraw Hill Professional.

[30] McKinney C., MBA, FHIMSS, PMP Ray Hess, MSA, RRT, FHIMSS, Whitecar M., MIS, LCDR, MSC, USN (2012), Implementing Business Intelligence in Your Helthcare Organization, HIMSS, USA, pp. 73-86.

[31] Miyim A., Muhammed M. (2019), "Smart Traffic Management System", 15th International Conference on Electronics, Computer and Computation (ICECCO), Abuja, Nigeria, pp. 1-6.

[32] Nyalungu V. (2011), "The application of a Business Intelligence tool for strategic planning in a higher education institution: a case study of the University of the Witwatersrand", The Journal for Transdisciplinary Research in Southern Africa, 7(1), pp. 53-72.

[33] Octoparse, 2021, Data Collection - The First Step of Business Intelligence, retrieved from https://www.octoparse.com/blog/data-collection-thefirst-step-of-business-intelligence.

[34] Olshannikova E., Ometov A., Koucheryavy Y., Olsson T. (2016): Visualizing Big Data, Big Data Technologies and Applications, p. 101-131.

[35] Olszak C. M. (2021), Business Intelligence and Big Data: Drivers of Organizational Success, Taylor and Francis, CRC Press. USA.

[36] Olszak C. M., Zurada J. (2015), "Information Technology Tools for Business Intelligence Development in Organizations", Polish Journal of Management Studies, 12(1), pp. 132-139.

[37] Olszak C. M. (2014), "Towards an Understanding Business Intelligence. A Dynamic Capability-Based Framework for Business Intelligence", Proceedings of the 2014 Federated Conference on Computer Science and Information Systems, pp. 1103-1110.

[38] Prabhu P., Anbazhagan N. (2014), "New hybrid algorithm for business intelligence recommender system", International Journal of Network Security \& Its Applications (IJNSA), 6 (2), pp. 43-52.

[39] Ranti K., Tuapattinaya D., Chang C., Girsang A. (2020), "Data warehouse for analysing music sales on a digital media store", Journal of Physics: Conference Series, Vol. 1477, Computer Science, pp. 032013, retrieved from https://iopscience.iop.org/article/10.1088/17426596/1477/3/032013.

[40] Sagiroglu S., Sinanc D. (2013), Big Data: A Review, Collaboration Technologies and Systems (CTS). International Conference on Digital Object Identifier, pp. 42-47.

[41] Sany N., Nurjanah U. (2019), "Executive information system at education institution on sma negeri 11 tangerang", Incomtech, Research Journal in Informatics and Communication Technology, 8 (2), pp. 23-27.

[42] SAS (2021), Analiza statystyczna. Rozejrzyj się wokół siebie. Statystyka jest wszędzie, retrieved from https://www.sas.com/pl_pl/insights/analytics/statisticalanalysis.html. 
[43] Smith K., Seligman L., Rosenthal A., Kurcz C., Greer M., Macheret C., Sexton M., Eckstein A. (2014), "Big Metadata: The Need for Principled Metadata Management in Big Data Ecosystems", Proceedings of Workshop on Data analytics in the Cloud (DanaC'14), Association for Computing Machinery, New York, USA, pp. 1-4.

[44] Sharma A., Tripathi K. (2021), Hybrid Version of Apriori Using MapReduce. Mobile Radio Communications and 5G Networks, Springer, pp. 585-592.

[45] Tableau (2020), "Business Intelligence Examples, 5 real examples of business intelligence in action", retrieved from https://www.tableau.com/learn/articles/businessintelligence-examples.

[46] Tufano A., Accorsi R., Manzini R. (2020), "Machine learning methods to improve the operations of 3PL logistics", Procedia Manufacturing, 42, pp. 62-69.

[47] Van Citters A., Gifford A., Brady C., Dunitze J., Elmhirst M., Flath J., Laguna T., Moore B., Pricketth M. Riordani M., Savant A., Gore W., Jian S., Soper M., Marshall B., Nelson E., Sabadosa K. (2020), "Formative evaluation of a dashboard to support coproduction of healthcare services in cystic fibrosis", Journal of Cystic Fibrosis, 19(5), pp. 768-776.

[48] Vellido A., Martín-Guerrero J., Rossi F., Lisboa P. (2011), "Seeing is believing: The importance of visualization in real-world machine learning applications". Conference: ESANN 2011, 19th European Symposium on Artificial Neural Networks, Bruges, Belgium, April 27-29, 2011, Proceedings.

[49] Ventocilla E., Riveiro M. (2020), "A comparative user study of visualization techniques for cluster analysis of multidimensional data sets". Information Visualization. Vol. 19 (4). pp. 318 - 338.

[50] Wexler S., Shaffer J., Cotgreave A. (2017): "The Big Book of Dashboards: Visualizing Your Data Using RealWorld Business Scenarios". 1st ed. Wiley Publishing.

[51] WHO, 2020, Covid Cases Dashboard, retrieved from https://covid19.who.int/.World Bank, 2010, World Bank, United Nations Natural Hazards, Unnatural Disasters: The Economics of Effective Prevention, Washington, D.C.: World Bank, pp. 4.

[52] World Bank, 2010, World Bank, United Nations Natural Hazards, Unnatural Disasters: The Economics of Effective Prevention, Washington, D.C.: World Bank, pp. 4.

[53] Yermalovich P. (2020), "Dashboard Visualization Techniques in Information Security". 2020 International Symposium on Networks, Computers and Communications (ISNCC), 1, pp. 25-30.

[54] Yigitbasioglu O., Velcu O. (2012), "A review of dashboards in performance management: Implications for design and research", International Journal of Accounting Information Systems", 13(1), pp. 41-59.

[55] Yousf E., Othman M. (2012), "A Review on the Dashboard Characteristics for Manufacturing Organizations", Journal of information systems research and innovation, 2, pp. 28-34.

[56] Yurtay Y., Ayanoğlu, M. (2021), "Dashboard application model in supplier evaluation by using artificial immune system and data mining methods". Pamukkale
Üniversitesi Mühendislik Bilimleri Dergisi, 27 (2), pp. 162-172.

[57] Zhou X., Tao X., Rahman M. (2017), "Coupling topic modeling in opinion mining for social media analysis". Proceedings of WI '17, Leipzig, Germany, August 23-26, 2017, pp. 533-540. 